\title{
ANÁLISE SOBRE A DEVOLUÇÃO DA CRIANÇA E DO ADOLESCENTE NO PROCESSO DE ADOÇÃO: DANOS PSICOLÓGICOS E A POSSIBILIDADE DE RESPONSABILIDADE CIVIL
}

\author{
Carla Bertoncini ${ }^{1}$ \\ Laísa Fernanda Campidelli ${ }^{2}$
}

Resumo: Considerando o princípio constitucional da proteção integral do menor, o presente artigo estuda a ocorrência da devolução no processo de adoção e suas consequências psicológicas aos menores envolvidos. Para tanto, procedeu-se à pesquisa bibliográfica, e principalmente, à análise de julgados, sendo o estudo desenvolvido por meio do método dedutivo. Desse modo, verificou-se que os menores envolvidos nos processos de adoção são devolvidos mediante justificativas questionáveis, as quais, muitas vezes, refletem a impensada decisão dos candidatos a pais de serem pais e mães. Conclui-se que esta situação pode gerar danos psicológicos inestimáveis nos menores, passíveis, inclusive, de responsabilização civil.

Palavras-chave: ECA. Adoção. Devolução. Danos psicológicos. Responsabilidade civil.

\section{ANALYSIS ON THE RETURN OF THE CHILD AND ADOLESCENT IN THE ADOPTION PROCESS: PSYCHOLOGICAL DAMAGE AND THE POSSIBILITY OF CIVIL LIABILITY}

\begin{abstract}
Considering the constitutional principle of the minor's integral protection, the present article studies the return occurrence in the adoption process and its psychological consequences to the minors involved. Thus, a bibliographical research was carried out, mainly, the analysis of court cases, being the research developed by the deductive method. It was found that the minors involved in the adoption processes are returned by questionable justifications, which often reflect the thoughtless decision of the candidates for parents of being fathers and mothers. It is concluded that this situation can generate invaluable psychological damage to the minors, liable even of civil liability.
\end{abstract}

Keywords: ECA. Adoption. Devolution. Psychological damage. Civil Liability.

\footnotetext{
${ }^{1}$ Advogada. Profa. de Direito de Família e Sucessões da UENP. Profa. do Mestrado em Direito da UENP. Doutora em Direito Civil pela PUC-SP. E-mail: carla.bertoncini@uenp.edu.br.

${ }^{2}$ Mestranda em direito pela Universidade Estadual do Norte do Paraná. Graduada em direito pela Universidade Estadual do Norte do Paraná. Bolsista CAPES. Integrante do grupo de pesquisa GP CERTOS. Email:laisacampidelli@gmail.com.
} 


\section{INTRODUÇÃO}

A adoção é um eficaz mecanismo de garantia do direito a convivência familiar, o qual está expresso na Constituição Federal de 1988, no ECA e em diversos outros dispositivos. Porém, o tema demanda bastante cautela, uma vez que uma adoção infrutífera pode gerar danos inimagináveis ao menor envolvido nesse processo.

O presente trabalho tem como objetivo visualizar a ocorrência da devolução no contexto brasileiro, analisando principalmente as razões que levam os candidatos a pais a desistirem do desejo de adotar, assim como os danos causados a uma criança ou adolescente que é obrigado a voltar para a instituição de acolhimento, podendo, inclusive, voltar sozinho, pois seu irmão biológico pode permanecer na família adotiva.

A criança e o adolescente que vão para a instituição de acolhimento levam consigo uma bagagem comumente marcada por traumas e dores. O segundo abandono tem como tendência ser muito mais traumático que o primeiro; por essa razão, cabe ao Direito zelar para que essa situação não ocorra e, caso aconteça, que exista a responsabilização civil dos candidatos a pais, comprovado o não cumprimento da responsabilidade e do zelo que se espera de uma decisão dessa relevância.

O estudo desenvolver-se-á pelo método dedutivo, por meio de revisões bibliográficas, as quais envolvem aspectos jurídicos e psicológicos pertinentes ao conhecimento necessário para realizar a análise jurisprudencial de julgados recentes relativos à devolução de crianças e adolescentes, buscando-se a aproximação entre a doutrina e a prática.

\section{A "DEVOLUÇÃO” DE CRIANÇAS E ADOLESCENTES}

A adoção trata-se de medida excepcional - e, principalmente, irrevogável - utilizada nos casos de impossibilidade de que a família biológica cuide de seus filhos. É uma das modalidades de colocação em família substituta ${ }^{3}$ (Art. 19; Art. 39, § 1º, ECA). Ou seja, entende-se que já houve todas as tentativas de permanência na família biológica e que estas

\footnotetext{
${ }^{3}$ Art. 19. É direito da criança e do adolescente ser criado e educado no seio de sua família e, excepcionalmente, em família substituta, assegurada a convivência familiar e comunitária, em ambiente que garanta seu desenvolvimento integral. (ECA).
} 
restaram infrutíferas ${ }^{4}$, já tendo a criança sofrido os traumas decorrentes disso e da permanência em instituição de acolhimento.

Em aspectos conceituais, a adoção é "o ato jurídico solene pelo qual alguém recebe em sua família, na qualidade de filho, pessoa a ela estranha" (GONÇALVES, 2017, p.374). Destaca-se que existem autores civilistas que entendem que a adoção tem aspectos de negócio jurídico, por se tratar de iniciativa da parte e do exercício da autonomia privada pelo adotante, uma vez que a adoção não pode ser imposta, como ocorre com o reconhecimento de filho (TARTUCE, 2017, p. 489).

Quando a adoção não se concretiza, ocorre o que os doutrinadores denominam de "devolução". O uso desse termo faz referência direta a uma relação de consumo, em que o consumidor insatisfeito com a qualidade do produto o devolve por não atender as suas expectativas (PINHO, 2014, p.534). Assim, a criança ou o adolescente não supriu os desejos e anseios idealizados pelos candidatos a pais e é devolvida à instituição de acolhimento.

Porém, não é só na família substituta que ocorre a devolução. O primeiro abandono, bem recorrente, acontece na família extensa, a qual acaba por aceitar a incumbência de cuidar da criança ou do adolescente por um ímpeto inicial de solidariedade familiar, acolhendo, muitas vezes, parentes com que nem tinham vínculos de afetividade. Ocorre que isso não é suficiente, não havendo ninguém que assuma os papéis parentais, acabando por findar na devolução na primeira dificuldade (DIAS, 2017, p. 132).

Segundo Logstrup (apud BAUMAN, 2004, p. 81), "a compaixão é espontânea porque a menor interrupção, a menor maquinação, a menor diluição para que sirva a algum outro propósito provocam sua destruição total - na verdade, transformam-na em seu oposto, a desumanidade". Questiona-se que essa seja uma das precauções que deveria haver até em casos de entrega à família extensa para evitar a devolução.

Na preparação desses futuros pais, os psicólogos são orientados a atentar aos fatores motivacionais para a entrega à família extensa - em tese somente com quem a criança tivesse vínculos afetivos - e nas adoções. Destaca-se:

\footnotetext{
${ }^{4}$ Art. $19 \S 3^{\circ}$ A manutenção ou a reintegração de criança ou adolescente à sua família terá preferência em relação a qualquer outra providência, caso em que será esta incluída em serviços e programas de proteção, apoio e promoção, nos termos do $\S 1$ o do art. 23, dos incisos I e IV do caput do art. 101 e dos incisos I a IV do caput do art. 129 desta Lei (ECA).

Art $19 \mathrm{~A} \S 4^{\circ}$ Na hipótese de não haver a indicação do genitor e de não existir outro representante da família extensa apto a receber a guarda, a autoridade judiciária competente deverá decretar a extinção do poder familiar e determinar a colocação da criança sob a guarda provisória de quem estiver habilitado a adotá-la ou de entidade que desenvolva programa de acolhimento familiar ou institucional (ECA).
} 
Em sede de pretensão para adoção, é necessária a atuação de profissionais altamente qualificados, a fim de que o processo de colocação da criança ou do adolescente no lar substituto seja fechado com "chave de ouro", já que, em muitos casos, os momentos vivenciados com a chegada da criança ou adolescente chegam a se mostrar tão crônicos, que a dificuldade de separação das questões jurídicas das questões psicológicas se faz altamente presente (LADVOCAT, 2014, p.124).

Entretanto, mesmo com todo empenho dos profissionais que realizam a preparação e o processo de adoção junto aos pretendentes, não é possível assegurar que, nessa fase, todos aqueles não propensos a serem verdadeiros pais seriam reconhecidos.

Para Pinho (2014, p.535), algumas particularidades dos casais só serão descobertas quando estiverem em contato com a criança ou o adolescente a ser adotado, uma vez que no processo de habilitação são constantemente vislumbradas expectativas fantasiosas em relação à chegada do menor à família. Quando ocorre uma desistência no processo de adoção, é frequente tentar encontrar erros no procedimento de adoção, acreditando ser possível que a equipe anteveja os obstáculos que surgirão quando a família conhecer de fato a criança. Nos casos analisados pela autora, não foi possível estabelecer uma relação direta entre dificuldades na habilitação e desistência da adoção de crianças e adolescentes.

Além disso, muitos pais não estão preparados para lidar com os testes que os menores constantemente fazem pelo medo de serem rejeitados novamente (DIAS, 2017, p. 133).

Bauman (2004, p. 45) explica que, geralmente, relações de consumo fornecem amplas garantias; em contrapartida, nenhuma dessas garantias é oferecida na hora em que se escolhe ter um filho. As pessoas hoje chegam a buscar companhias que possibilitem a escolha de um filho num catálogo de doadores atraentes, além de clínicas que produzem por encomenda o espectro genético de um bebê em gestação, isso reflete um "produto conjunto do líquido ambiente da vida moderna e do consumismo como estratégia escolhida". Porém, trata-se de um equívoco acreditar que em uma relação desse porte pode-se ter controle, pois está além do alcance e da compreensão dos pais em potencial.

É possível fazer uma compreensão análoga quando se trata de adoção. Por mais que os pretensos pais delimitem as características da criança ou do adolescente que gostariam de adotar, vejam fotos antes e tenham a possibilidade de estar com a criança por um tempo, ainda assim, está muito além do alcance saber como esse menor vai vir a agir, ser, interagir no futuro. Nesse sentido, expõe Bauman que (2004, p. 45) "as alegrias da paternidade e da maternidade vêm, por assim dizer, num pacote que inclui as dores do auto-sacrifício e os 
temores de perigos inexplorados". Nesse sentido, é importante vislumbrar a possível frustação, como parte do todo, no ato do planejamento de uma ação:

Todos aprendemos às nossas próprias custas que mesmo os planos mais cuidadosos e elaborados têm a desagradável tendência de frustrar-se e produzir resultados muito distantes do esperado; que nossos ingentes esforços de "pôr ordem nas coisas" freqüentemente[sic] resultam em mais caos, desordem e confusão; e que nosso trabalho para eliminar o acidente e a contingência é pouco mais que um jogo de azar (BAUMAN, 2001, p. 157).

É presumível que, como todas as relações de pais e filhos, existam conflitos, dificuldades de aprender as regras, traumas que refletem atitudes grosseiras, dentre outras circunstâncias. Em análise de casos práticos, visualiza-se, que quando a criança não corresponde ao desejado, por vezes, o casal simplesmente desiste, sem pensar nas consequências geradas pelos seus atos. É o caso expresso no julgado a seguir, em que o casal ignora a relação construída entre irmãos, ficando somente com a irmã mais nova, devolvendo o outro à instituição:

[...] Tendo os pais adotivos abandonado o menor, devolvendo-o ao abrigo, não tendo demonstrado sequer um mínimo de esforço para reaproximarem da criança, patente o dever de indenizar, não só porque o filho foi privado do convívio de seus pais mas, primordialmente, de sua irmã de sangue de quem sente muita saudade. Negligenciando os requeridos na criação e educação do adotado, mormente, por terem ciência de que a adoção somente foi concedida, para possibilitar o convívio irmãos, ferindo, assim, o princípio constitucionalmente assegurado, da dignidade da pessoa humana, cabe-lhes indenizar a criança pelos danos sofridos (BRASIL, 2011).

É destacado que, desde o princípio, o casal tinha o interesse de adotar a irmã mais nova, assim como o fato de a relação com o menino nunca ter sido afetuosa. Desse modo, o que "o casal queria adotar era a menina, [...] , mas como os irmãos não podiam ser separados teve de levar o [...] 'como um contrapeso' e, depois de algum tempo, devolveu o contrapeso e ficou com a menina como se ficasse com a carne e devolvesse o osso" (BRASIL, 2011).

Outro fator relevante é a não intenção de se esforçar para reaproximarem-se da criança. É constante que os pretendentes busquem atendimento da Vara já estando decididos sobre a devolução da criança. Ademais, "a postura dos adultos envolvidos, culpando as crianças pelo fracasso na relação estabelecida, parece ser o ponto central dos casos de devolução" (PINHO, 2014, p. 536). 
Assim, deve haver a plena consciência de que, apesar de se tratar de uma criança ou de um adolescente, o qual não tem como se defender, ele é titular de direitos fundamentais 5 . Nessa perspectiva, Bauman(1998b, p. 22-23) cita como característica da modernidade o fato de que as pessoas "deleitam-se na busca de novas e ainda não apreciadas experiências, são de bom grado seduzidos pelas propostas de aventura e, de um modo geral, a qualquer fixação de compromisso, preferem ter opções abertas". Em análise ao caso prático já acima exposto, observou-se o entendimento de que o casal era responsável por ter feito a escolha pela adoção, a qual lhes proporcionou a condição de pais, devendo assumir as consequências advindas dos seus atos:

[...] cumpre frisar que não obstante tenham os pais adotivos, ora apelantes, tomado providências junto a Justiça, em vista das dificuldades que vinham encontrando na criação do adolescente, o certo é que, por sua própria vontade, o adotaram judicialmente (fls. 39/49), sendo que a adoção, nos termos do artigo 48 do ECA é irrevogável, atribuindo, a condição de filho ao adotado, com os mesmos direitos e deveres, inclusive, sucessórios. Assim, apesar de ter sido determinado judicialmente a ida do menor para instituição (fl. 182), essa determinação visava, precipuamente, melhorar o relacionamento familiar, tendo sido determinada com o intuito de que fosse possibilitado o tratamento da família e não como uma "devolução", sendo certo que os pais deveriam acompanhar de perto o menor, além de se sujeitarem a tratamento psicológico, o que não fizeram deliberadamente (BRASIL, 2011).

A situação resultou na transformação da criança em objeto, como se vê claramente na narrativa da psicóloga quando diz que o menor "foi um objeto nas mãos dos pais adotivos, foi manipulado, rejeitado e agredido em todas as áreas da sua vida”. Além disso, destacou que ele "não foi amado, nem respeitado, foi tratado como um objeto descartável, e ele traz esse estigma até hoje, prejudicando sua autoestima, seu desempenho escolar e até mesmo sua capacidade de relacionar com os outros" (BRASIL, 2011).

Ressalte-se também que, em se tratando de adoção de bebês, os pretendentes têm de estar plenamente conscientes de que - igualmente na paternidade biológica - existe a possibilidade de que ele tenha alguma doença ou deficiência ainda não aparente. Nesse

\footnotetext{
${ }^{5} \mathrm{ECA}$ Art. $3^{\circ} \mathrm{A}$ criança e o adolescente gozam de todos os direitos fundamentais inerentes à pessoa humana, sem prejuízo da proteção integral de que trata esta Lei, assegurando-se-lhes, por lei ou por outros meios, todas as oportunidades e facilidades, a fim de lhes facultar o desenvolvimento físico, mental, moral, espiritual e social, em condições de liberdade e de dignidade.

Parágrafo único. Os direitos enunciados nesta Lei aplicam-se a todas as crianças e adolescentes, sem discriminação de nascimento, situação familiar, idade, sexo, raça, etnia ou cor, religião ou crença, deficiência, condição pessoal de desenvolvimento e aprendizagem, condição econômica, ambiente social, região e local de moradia ou outra condição que diferencie as pessoas, as famílias ou a comunidade em que vivem.

Art. 15. A criança e o adolescente têm direito à liberdade, ao respeito e à dignidade como pessoas humanas em processo de desenvolvimento e como sujeitos de direitos civis, humanos e sociais garantidos na Constituição e nas leis.
} 
sentido, sendo a criança um ser humano e não um objeto passível de troca diante de defeito, esse tipo de conduta pode ter sua responsabilização civil diante de dano, uma vez que os pais devem passar por uma preparação ${ }^{6}$ antes da adoção, na qual lhes são explicadas as condições das crianças e adolescentes aptos à adoção, tal como questionado se estão realmente preparados para ser pai e mãe.

Essa situação fática não está distante dos tribunais. Vislumbrar os efeitos da tomada de decisão dos "antigos" pais em relação à criança que volta à instituição de acolhimento com ainda menores chances de uma adoção bem sucedida, trata-se de medida necessária à preservação do melhor interesse do menor envolvido na questão:

O Parquet relata que a genitora do menor o entregou para adoção após o seu nascimento, tendo os requeridos protocolizado pedido de adoção e obtido a guarda provisória do menor. Afirma que o menor, em setembro de 2008, foi diagnosticado portador de doença congênita que provocou malformação do sistema nervoso central, e que os requeridos, depois de estarem mais de dois anos em companhia da criança, desistiram da adoção e devolveram a criança (BRASIL, 2014) (grifo nosso).

Devolver o menor, após dois anos com ele, é, no mínimo, agir de forma negligente, pois fizeram com que a criança acreditasse que aqueles eram seus pais durante 2 anos, para depois ser novamente abandonada. Fosse ela uma criança dita "perfeita", seu destino seria outro que não o abandono. É como a compra de um objeto idealizado na loja que, quando se descobre não ser o esperado, é devolvido. Mas aqui trata-se de uma criança já abandonada, inclusive pela mãe biológica, que vivencia seu segundo abandono. Assim:

\begin{abstract}
A criança não pode ser tratada como coisa só pelo fato de ser ela sem experiência ou sem atividade produtiva, sem maturidade espiritual, ou sem autoridade material. A criança, apesar de seu estado de extrema e concreta dependência, é um ser humano como qualquer outro, é um ser desejante e emotivo como qualquer outro, que sente dor diante da crueldade alheia e revolta por não lhe ser concedida à liberdade que é capaz de administrar sozinha. E é por ser dotada desse desejo e dessa necessidade que a criança, enfim é dotada de dignidade e assim deve ser respeitada. (HIRONAKA, 2002, p. 18)
\end{abstract}

Em atenção ao melhor interesse da criança e do adolescente, vislumbra-se entender que em dois anos sendo considerados pais, e tendo inclusive solicitado isso anteriormente, são aspectos necessários a serem analisados que:

\footnotetext{
${ }^{6} \mathrm{ECA}$ - "Art $50 \S 3^{\circ} \mathrm{A}$ inscrição de postulantes à adoção será precedida de um período de preparação psicossocial e jurídica, orientado pela equipe técnica da Justiça da Infância e da Juventude, preferencialmente com apoio dos técnicos responsáveis pela execução da política municipal de garantia do direito à convivência familiar".
} 
A criança não é mais objeto da intervenção da família e do Estado, mas titular de direitos, sujeito de direitos, os quais devem ser respeitados, principalmente pelos pais. Se descumprirem seu papel, os pais devem ser fiscalizados pela sociedade e pelo Estado e devem ser submetidos às medidas pertinentes, a fim de prevenir a ocorrência de ameaça ou violação aos direitos dos filhos. As medidas aplicáveis aos pais ou responsáveis estão previstas no art. 129, incs. I a X do Estatuto da Criança e do Adolescente e podem ser aplicadas pelo Conselho Tutelar (incs. I a VII) e pela autoridade judiciária (incs. I a X) (FERREIRA, 2000, p. 294).

Por outro lado, ainda existe a hipótese de ser o despreparo o responsável pelo fracasso. Entretanto, ressalta-se novamente aqui a questão da filiação biológica, em que também os pais se preparam com a vinda da criança ao seio familiar, tudo é construído. Com relação aos fracassos oriundos de adoções:

\begin{abstract}
Os fracassos acontecem não porque não se é consanguíneo, mas pelo contexto onde esta adoção foi criada. Os pais, muitas vezes, pela fantasia do medo da não adoção pelo filho, submetem e aprisionam a relação às provas de amor, impedindo a construção de laços afetivos livres em laços afetivos por obrigação. É a troca da devoção pela obrigação: você tem que amar, pois lhe demos algo (MARTINS, 2014, p. 711).
\end{abstract}

Nesse sentido, muitas vezes a motivação da adoção não é adequada e deve ser refletida com atenção antes da entrega efetiva da criança ao casal, para que não exista uma posterior devolução. No caso da infertilidade, o casal tem de viver o luto pelo filho biológico que não pode vir e trabalhar possíveis angústias referente a essa situação, para, assim, evitar possíveis dificuldades na relação com a criança ou o adolescente adotado (MORELLI; COMIN; SANTEIRO, 2015, p. 181). No mesmo sentido, concordam com esse posicionamento Farias e Rosenvald (2015, p. 908), ao afirmarem que é incorreto compreender o instituto da adoção como simples possibilidade de dar um filho para quem não pode tê-lo biologicamente, uma vez que isso seria entendê-lo como um substituto à frustação da procriação pelo método sexual.

Um outro estudo que analisou a devolução de 10 crianças no Rio de Janeiro mostrou que as motivações expostas pelos adotantes eram sempre comportamentos vinculados à faixa etária da criança ou ao histórico de abandono. Enquanto eles apresentavam a situação como dificuldade da criança, o que se pôde extrair é que a idealização feita pelos pretendentes não correspondia à realidade e eles não sabiam lidar com isso (LEVY, PINHO, FARIA, 2009, p. $58-63)$.

A preparação para a chegada do filho na adoção é tão essencial quanto na filiação biológica, significando que "gestar simbolicamente é se preparar para a chegada do filho, imaginar, sonhar e refletir sobre o exercício parental e, principalmente, trabalhar os fantasmas 
que povoam o imaginário do(s) adotante(s)" (MORELLI; COMIN; SANTEIRO, 2015, p. 189).

Nesse sentido, ressalta-se a questão das diferenças advindas da história não só pessoal da criança, como do contexto social em que ela estava e foi inserida, e de como isso influencia no processo de adoção:

[...] as relações envolvidas no processo das adoções devem ser consideradas quando se pretende discutir adoção, tanto de bebês quanto de crianças mais velhas. Discutir adoção partindo de avaliações sobre as crianças, ou sobre o passado das crianças, é tratar o assunto de forma unidirecional e parcial. O desenvolvimento de uma criança adotada não pode ser visto de maneira isolada, desconectado do contexto em que está inserido, das peculiaridades de relacionamentos de cada família adotante e dos elementos únicos que configuram a trajetória de cada criança (SOLON, 2006, p. 113).

Além disso, segundo psicólogos analisam, a reflexão sobre as reais motivações que envolvem a decisão de serem pais por adoção é essencial, refletindo, sobretudo, as crenças, muitas vezes equivocadas, herdadas culturalmente. Nesse momento, diluem-se expectativas irreais, além da idealização feita no desenrolar do tempo de espera, para que a adoção não se transforme em fracasso e frustração desmesurados, uma vez que esses contrapontos aos desejos humanos são inevitáveis (MORELLI; COMIN; SANTEIRO, 2015, p. 189).

Tendo em vista o exposto, observa-se que os casais constantemente agem sem pensar na consequência de seus atos em relação às crianças e adolescentes envolvidos. Além disso, apesar de um possível despreparo para lidar com a situação da maternidade e paternidade, o mesmo ocorreria na filiação biológica, em que o caminho seria, possivelmente, diferente de uma devolução.

Culpar a criança ou o adolescente pelo fracasso da adoção é questionável em virtude de, na maioria das vezes, esses menores terem o desejo de permanecer no seio familiar adotivo, mesmo que expressem determinadas condutas contrárias a isso, como forma de testar os novos pais.

Ademais, nada foi imposto aos pretendentes que buscaram a adoção. Por mais imprevisível que pudesse vir a ser a situação, eles foram o polo mais forte da relação. Além disso, tiveram a opção de escolha e, mesmo assim, optaram pela adoção. No momento em que decidiram ser pais por adoção, assumiram as consequências advindas desse compromisso, nem sempre positivas ou semelhantes às idealizadas. 
Em sequência, analisar-se-ão os aspectos psicológicos resultantes da devolução, para possivelmente fundamentar o debate acerca da possibilidade de responsabilização civil pelo dano causado.

\section{ASPECTOS PSICOLÓGICOS VINCULADOS À REJEIÇÃO}

A segunda devolução pode ser ainda mais difícil do que a primeira. A criança ou o adolescente confiou novamente, porém foi devolvida, como se não tivesse valor suficiente para que com ela ficassem. Os efeitos psicológicos que a narrada situação pode gerar são os mais diversos, impossíveis de serem quantificados ou descritos. Antes de conseguir analisar aspectos que forneçam substratos a uma possível reparação, menciona-se a questão da confiança para Bauman (2004, 80-81):

[...]A confiança foi condenada a uma vida cheia de frustração. Pessoas (sozinhas, individualmente ou em conjunto) empresas, partidos, comunidades, grandes causas ou padrões de vida investidos com a autoridade de guiar nossa existência freqüentemente [sic] deixam de compensar a devoção. De qualquer forma, é raro serem modelos de coerência e continuidade a longo prazo. Dificilmente há um único ponto de referência sobre o qual se possa concentrar a atenção de modo fidedigno e seguro, para que os desorientados possam ser eximidos do fatigante dever da vigilância constante e das incessantes retrações de passos dados ou pretendidos. Não se dispõe de pontos de orientação que pareçam ter uma expectativa de vida mais longa do que os próprios necessitados de orientação, por mais curtas que possam ser suas existências físicas. A experiência individual aponta obstinadamente para o eu como o eixo mais provável da duração e da continuidade procuradas com tanta avidez.

São constantes as descrições de psicólogos os quais elencam as dificuldades que a criança tem de, posteriormente, estabelecer vínculos, pois acaba perdendo a confiança que depositava nos relacionamentos. Conforme descrição de uma psicóloga, referindo-se a uma criança institucionalizada há três anos: "A criança encontra grande dificuldade de manter relacionamentos por conta das inúmeras perdas que já sofreu, que sente a falta de ter uma família para si e de poder compartilhar desse convívio" (VOLTOLINI, 2016).

A convivência familiar é importante para o crescimento sadio de toda criança e adolescente, pois proporciona, dentre outros benefícios, o apego. Segundo Cuneo (2012, p. 420) “o apego é um vínculo afetivo desenvolvido pelo indivíduo em relação a um parceiro que, por sua importância, deseja-se que sempre esteja próximo e que não pode ser substituído por nenhum outro". Nesse mesmo sentido: 
O atraso no desenvolvimento do apego indica que a criança, por alguma razão, experimentou muito menos estimulação social de uma figura materna, como é o caso das que são criadas em instituições, devido à forma impessoal dos cuidados que geralmente lhe são dispensados. A qualidade da interação social entre a figura materna e a criança possibilita o rápido desenvolvimento por parte desta do apego discriminado, ao passo que sem devida estimulação todo esse processo torna-se muito mais lento. A experiência de uma criança junto a uma figura de apego que a estimule, seja cooperativa e a apoie auxilia significativamente o indivíduo a construir um modelo favorável para formar futuros relacionamentos, além de promover seu senso de confiança e competência (CUNEO, 2012, p. 421).

Além disso, frequentemente, quando uma criança ou adolescente é devolvido, desenvolve um sentimento de culpa pela situação que enfrenta. É como se seu futuro lar não fosse mais ser seu por culpa exclusiva sua. Ela caracteriza o que está passando como forma de castigo por sua conduta. Nesse sentido, destaca-se que esses menores podem não se recuperar desse segundo trauma, devendo, por essa razão, receber atenção dos responsáveis pelas decisões judiciais que os envolvam (LADVOCAT, 2014, p. 124).

O que se busca evidenciar é que a criança e o adolescente são o polo mais vulnerável dessa situação, não devendo o Direito resguardar o mais forte (os pais), e sim o menor, já abandonado uma vez, dependente do Estado e com seu futuro ameaçado pela conduta daqueles que diziam que seriam seus maiores protetores, seus pais.

No caso já citado no tópico acima, o adolescente foi devolvido e separado de sua irmã - com a qual mantinha vínculos de afetividade - para uma possível tentativa de construção de vínculo. Porém observou-se que os pretensos pais iam visitá-lo poucas vezes e, quando o faziam, impunham sempre mais angústia e humilhação. O relatório da psicóloga dizia que o possível pai "se referia a ele como: retardado, burro, moleque e acusava a criança de ter destruído seu casamento; indagava também se ele já tinha consertado, pois, se tivesse, poderia voltar a morar com eles". Nesse contexto, observa-se que o adolescente ficava confuso, pois, apesar de tudo, ainda dizia a todos que aqueles eram seus pais. Em contrapartida, o casal mostrava desinteresse em relação a uma possível tentativa de reaproximação e construção de vínculos, proposta pela psicóloga (BRASIL, 2011). A situação gerou na criança:

[...] a criança sentiu muito a devolução e todos os dias tinha a expectativa de voltar para o casal; presenciou algumas visitas do casal depois da devolução do menor; as visitas se processavam da seguinte maneira: o casal chegava, se posicionava um pouco distante e com os braços cruzados; o casal fazia perguntas à mãe social nos seguintes termos: esse moleque já consertou, já está prestando, porque ele quase destruiu nosso casamento, isto tudo dito na frente da criança; o V. se mantinha com 
muita agonia e em cada visita ele perguntava: "hoje eu já vou" "Você já vai me levar" e o casal dava muita esperança de que iria levá-lo [...](BRASIL, 2011).

Além disso, o casal da narrada situação criou condições para que a criança desenvolvesse danos psicológicos. É destacado que eles perguntavam se a criança havia deixado de ser um mau menino, fato que a constrangia por inteiro, somado ainda à constante rejeição, como ocorrido em um evento em que o pretenso pai agrediu na nuca o menino por ele ter se agarrado aos seus pais frente à expectativa de ser levado novamente para casa. Destaca-se que "a atitude do casal era de desprezo; não sabe informar porque o casal ia visitar o [...], mas talvez por desencargo de consciência ou para alimentar a esperança do menino; depois que o casal ia embora, o [...] ficava muito triste e muito agressivo" (BRASIL, 2011).

A despeito de cada criança reagir de uma forma à situação que vivencia, são comuns reações agressivas, expressadas através de xingamentos e provocações verbais aos próprios cuidadores dessas crianças (CUNEO, 2012, p. 428). Assim, as pioras no comportamento são frequentes, como se observa no caso prático a seguir:

[...] Alegação de ausência de provas quanto ao agravamento dos traumas no infante. Argumento afastado. Conjunto probatório suficiente a demonstrar a piora comportamental da criança nos momentos posteriores a cada devolução. Agravamento do estado emocional. Inegável dano psicológico à criança. Pedido de minoração do quantum indenizatório não acolhido. Valor adequado as particularidades do caso concreto. Recurso conhecido e desprovido. (BRASIL, 2017).

Um outro fato comum é que alguns casais, após adotarem por histórico de infertilidade, e diante da possibilidade de terem um filho biológico, acabam deixando o filho adotado em segundo plano ou até mesmo o devolvem sob justificativas banais. É o caso do menino Billy, que foi devolvido após o nascimento do filho biológico, mesmo tendo vivido muito tempo com a família que pretendia adotá-lo:

Após um mês no abrigo, Billy com 3 anos e 11 meses, foi colocado em uma família adotante. Tratava-se de um casal que havia feito cadastro no Fórum com opção para bebês até 1 ano. O casal foi chamado para conhecer a criança no abrigo, tendo manifestado interesse em adotá-lo. Casados há 4 anos, com história de infertilidade, a mulher tinha 29 anos e o marido, 36 anos. Ao retirarem Billy do abrigo, eles já suspeitavam de uma possível gravidez [...] Fui informada de que, na entrevista de acompanhamento (depois de 2 meses colocado - Billy já com 4 anos), a mãe adotiva se referia a ele como "o menino", que ele havia lhe dito um dia "hoje você não está bêbada" e que havia perguntado pelos irmãos. A Equipe Interdisciplinar marcou nova avaliação depois de 8 meses, prevendo o nascimento do filho biológico do casal. Porém, antes da data prevista, após dez meses de colocação, o pai procurou o setor psicossocial do fórum para pedir ajuda. Nesta época, o bebê já estava com 2 
meses. O pai queixava-se de que Billy fazia constantes referências à mãe biológica, apresentados birras e crises de choro durante a noite. A família foi encaminhada para atendimento psicológico. Uma semana depois, o pai ligou desejando devolvê-lo, pois sua esposa havia saído de casa com o bebê, após ter brigado com Billy (SOLON, 2006, p.59-60).

Após um ano e meio de convivência com a nova família, Billy foi novamente rejeitado e voltou para a instituição de acolhimento. O relatório psicossocial da criança retratou que ela estava triste, com fases de isolamento e mostrando um amadurecimento desproporcional a sua idade, resultando, inclusive, em necessidade de encaminhamento para atendimento psicológico (SOLON, 2006, p.60).

A rejeição é capaz de criar no indivíduo consequências adversas. Bauman (1999, p. 134-135) destaca que a exclusão e a rejeição são humilhantes e pretendem sê-lo, pois visam a que a vítima da rejeição comece a se ver como inferior e imperfeita socialmente.

Além disso, a descontinuidade de laços afetivos emocionalmente relevantes para o menor leva a dificuldades na estruturação do self e dirigem à insegurança pessoal, medo e falta de confiança no outro (CUNEO, 2012, p. 427).

A instituição não é suficiente para suprir todas as necessidades para o crescimento sadio de um menor, uma vez que ela proporciona um tipo de socialização que é representado pela inexistência ou carência de vínculos afetivos, que levam à ausência de um referencial cognitivo, fundamental a uma concepção de si mesmo (CUNEO, 2012, p. 422). Em continuidade, destaca-se o que a ocorrência de eventos como uma devolução pode causar:

\footnotetext{
A incidência de efeitos perniciosos aptos a causar desordem na formação do desenvolvimento do indivíduo é evidente. Distúrbios psiquiátricos e da personalidade podem ser derivados por uma falha no processo de formação de apego e de elaboração de vínculos afetivos estáveis. Não se pode olvidar que o orgânico, o psíquico, o emocional, o individual e o social são elementos integrantes da condição humana, pertencentes ao indivíduo e ao ambiente em que ele nasce, cresce e se desenvolve (CUNEO, 2012, p. 423).
}

Com relação aos impactos das adoções bem concretizadas, Dana Johnson realizou um estudo sobre os efeitos da adoção no desenvolvimento das crianças, trazendo reflexos positivos do instituto, até mesmo para aquelas mais negligenciadas na família anterior:

\footnotetext{
Mesmo para crianças que sofreram gravemente negligência e abuso no início da vida, uma família adotiva pode ser um ambiente excelente para elaboração do trauma emocional e físico, podendo reverter comprometimentos de desenvolvimento. Passado o momento de perda e crise, as crianças se recuperam e progridem para se tornarem adultos competentes funcional e emocionalmente. (JOHNSON apud SOLON, 2006, p. 14).
} 
Assim, os danos causados às crianças e adolescentes, apesar de serem difíceis de serem mensurados, são uma possibilidade evidente que merece ser estudada e tutelada pelo Estado, uma vez que esses menores vivenciam sua segunda rejeição em virtude de escolhas feitas por outras pessoas, nas quais eles depositaram confiança e esperança.

\section{FUNDAMENTAÇÕES PARA UMA POSSÍVEL RESPONSABILIZAÇÃO CIVIL}

Como se observou pelo exposto, a devolução de crianças e adolescentes motivada pelo não atendimento das expectativas desejadas pelos pretendentes a pais pode ocasionar danos inestimáveis aos menores. Desse modo, analisa-se a possibilidade de uma responsabilidade civil com reparação dos danos causados, questionando, principalmente, se o pagamento de determinada quantia, a título de indenização ou o pagamento de pensão mensal, é o suficiente para reparar o dano causado, principalmente o de ordem emocional.

Bauman (1998b, p. 73) destaca que o mundo passa por uma constante dificuldade, pois na medida em que é constante a percepção dos perigos a nossa frente, também o é a crescente sensação de impotência para evitá-los e aliviar-lhes a gravidade do impacto. Nesse sentido, apesar de parecermos ter evoluído, de estarmos cada vez melhores, na prática "as consequências das ações humanas repercutem com uma força cega e elementar, que lembra mais os terremotos, inundações e ciclones do que um modelo de comportamento racional e automonitorado".

Evidentemente que, quando se questionam os danos psicológicos causados por uma devolução, a reparação monetária não seria suficiente, a menos que o montante fosse empregado em tratamento psicológico completamente eficaz ou algo equivalente. Situação complexa, pois, por mais que exista um bom psicólogo e uma boa equipe interdisciplinar, nada supre a falta da família e o trauma sofrido.

Nesse sentido, a ausência da vida familiar impossibilita a atenção individualizada, constituindo dificuldade ao pleno desenvolvimento das potencialidades biopsicossociais da criança (CUNEO, 2012, p. 422). Então, por melhor que seja o tratamento proporcionado por uma instituição e pelos profissionais que a integram, dificilmente conseguirá se equiparar-se à vida em um lar.

A criança não é um adulto em miniatura. Ao revés, apresenta características e necessidades próprias de cada faixa etária, de acordo com as fases 
desenvolvimentais e o ciclo vital. Para um hígido desenvolvimento psicológico, tem necessidade da mantença de um relacionamento constante e ininterrupto, caracterizado por tocas afetivas e estimulação por parte de um adulto que lhe seja emocionalmente significativo (CUNEO, 2012, p. 423).

A Constituição Federal de $1988^{7}$ trouxe a possibilidade de indenização em casos de dano moral ou material. Além disso, o Código Civil ${ }^{8}$ expõe que aquele que causa dano a outrem, mesmo que de ordem moral, comete ato ilícito passível de indenização. Assim, cabe à parte que age com culpa reparar os danos que causou. A competência para ajuizar essas ações é do Ministério Público, por se tratar de menores sob a guarda do Estado, conforme Estatuto da Criança e do Adolescente (Lei $\mathrm{n}^{\circ}$. 8.069/90) ${ }^{9}$. O que se discute neste estudo é se a devolução de uma criança ou de um adolescente poderia gerar o direito a uma reparação e, caso a resposta seja positiva, em quais casos isso deveria ocorrer. Para fundamentar a possibilidade de um direito à indenização, pode-se citar o trecho do livro "o que é justiça", o qual menciona que o ser humano não pode ser usado de forma arbitrária pelo outro, como se não tivesse valor:

O que poderia ser um valor absoluto, como um fim em si mesmo? A resposta de Kant: a humanidade. "Eu digo que o homem, e em geral todo ser racional, existe como um fim em si mesmo, e não meramente como um ser que possa ser usado de forma arbitrária por essa ou aquela vontade. Essa é a diferença fundamental, lembranos Kant, entre pessoas e coisas. Pessoas são seres racionais. Não tem apenas um valor relativo: têm muito mais, têm um valor absoluto, um valor intrínseco. Ou seja, os seres racionais têm dignidade (apud SANDEL, 2012, p. 154).

Quando se questiona o papel da justiça no mundo moderno - o qual apresenta as características descritas por Bauman (1998b, p.89)- pode-se dizer que esse seja justamente o de identificar e combater injustiças, mas não como um "estado final” descritível, no sentido

\footnotetext{
${ }^{7}$ Art. $5^{\circ}, \mathrm{X}$ - são invioláveis a intimidade, a vida privada, a honra e a imagem das pessoas, assegurado o direito a indenização pelo dano material ou moral decorrente de sua violação;

${ }^{8}$ Art. 186. Aquele que, por ação ou omissão voluntária, negligência ou imprudência, violar direito e causar dano a outrem, ainda que exclusivamente moral, comete ato ilícito.

Art. 927. Aquele que, por ato ilícito (arts. 186 e 187), causar dano a outrem, fica obrigado a repará-lo.

Parágrafo único. Haverá obrigação de reparar o dano, independentemente de culpa, nos casos especificados em lei, ou quando a atividade normalmente desenvolvida pelo autor do dano implicar, por sua natureza, risco para os direitos de outrem.

${ }^{9}$ Art. 201. Compete ao Ministério Público: V - promover o inquérito civil e a ação civil pública para a proteção dos interesses individuais, difusos ou coletivos relativos à infância e à adolescência, inclusive os definidos no art. $220, \S 3^{\circ}$, inciso II, da Constituição Federal.

VIII - zelar pelo efetivo respeito aos direitos e garantias legais assegurados às crianças e adolescentes, promovendo as medidas judiciais e extrajudiciais cabíveis;

Art. 212. Para defesa dos direitos e interesses protegidos por esta Lei, são admissíveis todas as espécies de ações pertinentes.
} 
de que a justiça deve querer sempre mais de si mesma. Quando Kant menciona que existem diferenças entre pessoas e coisas, tendo as pessoas um valor absoluto, deve-se primar justamente para que sua dignidade seja sempre preservada.

Muitas vezes os "ex-pais" querem demonstrar que a culpa não lhes pertence, como no recurso interposto por um desses, o qual citava que "na Audiência de Instrução e Julgamento, ficou claro e evidente que os Apelantes não deram motivo para a devolução do menor a instituição" (BRASIL, 2011). Diante disso, discute-se aqui se é correto tentar transferir a culpa para o outro. Bauman (1998b) traz considerações acerca de conflitos em que se aponta quem está com a verdade:

\begin{abstract}
A noção de verdade pertence à retórica do poder. Ela não tem sentido a não ser no contexto de oposição - adquire personalidade própria somente na situação de desacordo, quando diferentes pessoas se apegam a diferentes opiniões, e quando se torna o objeto de disputa de quem está certo e quem está errado - e quando, por determinadas razões, é importante para alguns ou todos os adversários demonstrar ou insinuar que é o outro lado que está errado. Sempre que a veracidade de uma crença é contestada, ou se prevê que seja contestável. A disputa acerca da veracidade ou falsidade de determinadas crenças é sempre simultaneamente o debate acerca do direito de alguns de falar com a autoridade que alguns outros deveriam obedecer; a disputa é acerca do estabelecimento ou reafirmação das relações de superioridade e inferioridade, de dominação e submissão, entre os detentores de crenças (1998b, p. 143).
\end{abstract}

Nesse sentido, considera-se que a adoção deve ser vista com mais seriedade pelos candidatos que, por livre arbítrio, decidem adotar. Assim, devem ter consciência e comportamento de verdadeiros "pais", que deduzem o ímpeto de encarar os obstáculos e condições adversas que ocorrerem em benefício da criança adotada, responsabilizando-se de forma incondicional como filho, para que seja possível a formação do vínculo familiar (BRASIL, 2014).

As famílias que se dispõem a adotar crianças que já sofreram uma primeira rejeição pelo menos da família biológica - adotam-nas com seu passado, suas memórias, seus traumas e devem assumir a incumbência de serem pais, tendo cuidado e zelo por elas, seja como for. A partir dos ensinamentos no novo lar ela, com o tempo, refletirá as mudanças e a nova família. Abandoná-la no meio do percurso não só dificulta a formação do seu ser, como também prejudica o seu crescimento sadio.

Os pais alegam, muitas vezes, motivações de "foro íntimo", porém isso não se justifica, sendo considerado conteúdo vazio e configurando uma desistência imotivada 
(BRASIL, 2014). Além disso, querem culpar a criança pela situação, como já mencionado acima:

\begin{abstract}
AÇÃO RESCISÓRIA. AÇÃO DE ADOÇÃO. Adotantes que, transcorridos poucos meses do trânsito em julgado da adoção, manifestaram o intento de devolução da criança ao abrigo, sob a justificativa de mau comportamento e de convivência tumultuada. Reacolhimento determinado pelo juízo a quo. Interposição do pleito rescisório baseado em erro de fato e na existência de prova nova. Art. 966, incisos VII e VIII do CPC/2015. Entretanto, sonegação de informações relevantes que não se verifica. Mãe da menor que é portadora do vírus HIV. Dado que consta dos documentos juntados na ação de adoção. Consentimento do casal adotante em prosseguir com o feito. Outrossim, prazo exíguo do estágio de convivência. Mácula que igualmente não se verifica. Procedimento do art. 46 do ECA devidamente respeitado. Acompanhamento e avaliações pela equipe interdisciplinar desde a aproximação da criança com o casal, da guarda provisória até a concessão da adoção. Laudos e relatórios que revelam a boa construção de vínculos afetivos entre adotantes e adotanda nesse período de 8 (oito) meses. Rescisão do comando sentencial inviável sob estes fundamentos. Improcedência. (BRASIL, 2017).
\end{abstract}

Em algumas situações, a pessoa que decide adotar passa um tempo considerável com a criança, como do caso acima de 8 meses, para depois devolvê-la quando esta já considerava a nova casa seu lar. As alegações de "mau comportamento e de convivência tumultuada" são questionáveis, pois crianças e adolescentes em formação podem ser educados e mudar seus comportamentos mediante paciência, empatia, posicionamentos que pessoas realmente dispostas a ser pai e mãe assumiriam em prol de seus filhos.

Nesse sentido, ter a liberdade de escolher, mas também - e talvez mais importante - a liberdade em relação às consequências da escolha errada e, portanto, a liberdade dos atributos menos atraentes da vida de escolhas (BAUMAN, 2001, p. 104). Ou seja, a responsabilização pelos danos causados deve ser refletida, uma vez que, como já vislumbrado, as crianças e adolescentes saem desse contexto, frequentemente, com consequências psicológicas relevantes, as quais poderão afetá-las por toda a vida.

Ressalta-se que os antigos candidatos a pais retornam a sua vida antiga, livrando-se daquilo que não querem mais e devolvendo-o. Porém, o menor volta à instituição levando consigo - em muitos casos -,a dor, a rejeição, o sentimento de não pertencer a lugar algum. Tudo isso precisa ser considerado, pois a justiça deve objetivar o zelo para com os mais vulneráveis, visto que, evidentemente, essas crianças correm o risco de terem seu crescimento sadio prejudicado, o que interfere negativamente no seu presente e prognostica seu futuro, justificando-se, assim, a possibilidade de uma responsabilização civil. 


\section{CONSIDERAÇÕES FINAIS}

O casal, quando decide adotar, tem de ter plena consciência de que não se trata de uma relação de consumo em que, se o produto não for bom, existe a possibilidade de devolvê-lo. Situação semelhante observar-se-ia na filiação biológica. Não é garantido que o filho terá o comportamento perfeito ou que não poderá vir a desenvolver determinada doença e necessite de cuidados.

A criança e o adolescente, ao contrário do adulto, estão em desenvolvimento da sua personalidade e identidade. Podem-se considerar inestimáveis os danos que uma devolução pode causar, não só para o presente como para o futuro. Assim, o menor não pode ser "coisificado" e devolvido mediante justificativas banais. Os pretendentes a pais estão assumindo o risco de o filho não ser igual ao idealizado, devendo, portanto, serem responsabilizados pela sua conduta, pois mesmo assim optaram pela adoção.

Assim, é necessário que o Estado realmente se empenhe em garantir os interesses das crianças e adolescentes institucionalizados para que condutas impensadas e irrefletidas feitas pelos candidatos, os quais optaram pela adoção, caso os prejudiquem, sejam responsabilizadas civilmente.

Reflete-se que, apesar de a quantia financeira ser incapaz de restaurar os danos psicológicos já causados, o dinheiro poderá ser investido em benefício da criança e do adolescente, garantindo-lhes melhor tratamento psicológico e médico, além de também poder possibilitar-lhes melhores condições de educação.

Dessa forma, destaca-se que, por não ser possível coagir o pretendente a ficar com o menor - porque isso não seria nem benefício ao seu melhor interesse -, deveria, sim, haver a indenização para que esse tipo de conduta não seja praticada nos processos de adoção, tal como existir recursos para que a criança ou o adolescente tenha suas necessidades materiais e psicológicas (como um possível tratamento) supridas, mesmo que de volta à instituição. 


\section{REFERÊNCIAS}

BAUMAN, Zygmunt. Amor líquido: sobre a fragilidade dos laços humanos. Rio de Janeiro: Jorge Zahar, 2004.

. Globalização: As Consequências Humanas. Tradução de Marcus Penchel. Rio de Janeiro: Jorge Zahar, 1999.

Zahar, 1998a.

Modernidade e Holocausto. Tradução de Marcus Penchel. Rio de Janeiro: Jorge

Modernidade Líquida. Tradução de Plínio Dentzien. Rio de Janeiro: Jorge Zahar, 2001.

O mal-estar da pós modernidade. Tradução Mauro Gama e Cláudia Martinelli Gama. Rio de Janeiro: Jorge Zahar, 1998b.

BRASIL. Constituição da República Federativa do Brasil de 1988. Brasília, DF: Senado Federal, 1988.Disponível em: <http://www.planalto.gov.br/ccivil_03/constituicao/constituicao.htm>. Acesso em 15 de ago. 2018.

Lei n. 8.069, de 13 de julho de 1990. Dispõe sobre o Estatuto da Criança e do Adolescente e dá outras providências. Disponível em: <http://www.planalto.gov.br/ccivil_03/Leis/L8069.htm>. Acesso em 15 de ago. 2018.

. Lei ${ }^{\circ}$ 10.406, de 10 de janeiro de 2002. Institui o Código Civil. Disponível em: <http://www.planalto.gov.br/ccivil_03/leis/2002/110406.htm>. Acesso em 15 de ago. 2018.

. Lei $\mathrm{n}^{\circ} 12.010$, de 3 de agosto de 2009. Dispõe sobre adoção. Disponível em: < https://www.planalto.gov.br/ccivil_03/_ato2007-2010/2009/lei/112010.htm>. Acesso em 15 de ago. 2018.

.Tribunal de Justiça de Minas Gerais. Apelação Cível nº 1.0702.09.5686482/002. Relator: Des. Teresa Cristina da Cunha Peixoto, 16 de novembro de 2011. Pesquisa de Jurisprudência. Disponível em: < http://www.ibdfam.org.br/jurisprudencia/>. Acesso em: 10 ago. 2018.

.Tribunal de Justiça de Minas Gerais. Apelação Cível nº 10481120002896002. Relator: Des. Hilda Teixeira da Costa, 12 de agosto de 2014. Pesquisa de Jurisprudência. Disponível em: < http://www.ibdfam.org.br/jurisprudencia/>. Acesso em: 10 ago. 2018.

.Tribunal de Justiça de Santa Catarina. Apelação Cível nº 090003943.2014.8.24.0064. Relator: Des. Jairo Fernandes Gonçalves, 05 de abril de 2017. Pesquisa de Jurisprudência. Disponível em: < http://www.ibdfam.org.br/jurisprudencia/>. Acesso em: 10 ago. 2018. 
CUNEO, Mônica Rodrigues. ABRIGAMENTO PROLONGADO: OS FILHOS DO ESQUECIMENTO. In: A Institucionalização Prolongada de Crianças e as Marcas que Ficam. Censo da população infanto-juvenil abrigada no Estado do Rio de Janeiro. Rio de Janeiro: 2012.

DIAS, Maria Berenice. Filhos do Afeto- Questões Jurídicas. 2a Ed. São Paulo: Editora Revista dos Tribunais, 2017.

FARIAS, Cristiano Chaves de. ROSENVALD, Nelson. Curso de Direito Civil, volume 6: direito de família. São Paulo: Atlas, 2015.

FERREIRA, Lúcia Maria Teixeira. Tutela da Filiação. In: Pereira, Tânia da Silva (Coord.). O Melhor interesse da criança: um debate interdisciplinar. Rio de Janeiro: Renovar: 2000.

GONÇALVES, Carlos Roberto. Direito Civil Brasileiro - volume 6: direito de família. 14. Ed. São Paulo: Saraiva, 2017.

HIRONAKA, Giselda Maria Fernandes Novaes. Direito e Responsabilidade (Coord. Coautora). Belo Horizonte: Del Rey, 2002.

LADVOCAT, Christiane. Devolução de Crianças em Guarda Provisória: Consequências Jurídicas do Rompimento. In: LADVOCAT, Cynthia et al. Guia de Adoção: No Jurídico, no Social, no Psicológico e na Família. São Paulo: Roca, 2014. Cap. 10. p. 123-137.

LEVY, Lídia; PINHO, Patrícia Glycerio R.; FARIA, Márcia Moscon de. Família e muito sofrimento: um estudo de casos de "devolução" de crianças. Psico. Porto Alegre:PUCRS, v.40, n.1, p.58-63, jan./mar. 2009.

LÔBO, Paulo Luiz Netto. Socioafetividade no Direito de Família: A Persistência de um Conceito Fundamental. In: Revista Brasileira de Direito das Famílias e Sucessões, $n^{\circ} 5$. Porto Alegre: Magister, 2007.

MARTINS, Silvana Garavello. Quando a adoção não acontece dos dos dois lados. In: LADVOCAT, Cynthia et al. Guia de Adoção: No Jurídico, no Social, no Psicológico e na Família. São Paulo: Roca, 2014. Cap. 58. p. 709-713.

MORELLI, Ana Bárbara; COMIN, Fabio Scorsolini; SANTEIRO, Tales Vilela. O "lugar" do filho adotivo na dinâmica parental: revisão integrativa de literatura. Psicol. clin., Rio de Janeiro ， v. 27, n. 1, p. 175-194, 2015. Disponível em $<$ http://pepsic.bvsalud.org/scielo.php?script=sci_arttext\&pid=S010356652015000100010\&ln $\mathrm{g}=\mathrm{pt \& nrm}=\mathrm{iso}>$. Acesso em 10 jul. 2018.

PINHO, Patrícia GlycerioR.. Devolução: Quando as crianças não se tornam filhos. In: LADVOCAT, Cynthia et al. Guia de Adoção: No Jurídico, no Social, no Psicológico e na Família. São Paulo: Roca, 2014. Cap. 45. p. 533-540.

SANDEL, Michael J. Justiça - O que é fazer a coisa certa. Tradução de Heloisa Matias e Maria Alice Máximo. Rio de Janeiro: Civilização Brasileira, 2012. 
SOLON, Lilian de Almeida Guimarães. A perspectiva da criança sobre seu processo de adoção. 2006, 202f. Dissertação (Mestrado) - Faculdade de Filosofia, Ciências e Letras de Ribeirão Preto, Universidade de São Paulo, Ribeirão Preto, 2006.

TARTUCE, Flávio. Direito Civil - Direito de Família. 12 edição. Rio de Janeiro: Forense, 2017.

VOLTOLINI, Roberta Fernanda. Crianças Devolvidas - O Desmoronar de um sonho. Disponível em: <http://robertavoltolini.com.br/criancas-devolvidas-o-desmoronar-de-umsonho/>. Acesso em: 20. Jun. 2018. 